
\title{
3 Research Square \\ The effect of propolis on 5-fluorouracil-induced cardiac toxicity in rats
}

\author{
Mohammad Barary \\ Babol University of Medical Sciences \\ Rezvan Hosseinzadeh \\ Babol University of Medical Sciences \\ Jackson J. Liang \\ University of Michigan \\ Razieh Mansouri \\ Babol University of Medical Sciences \\ Terence T. Sio \\ Mayo Clinic \\ Mohammad Hosseini \\ Islamic Azad University \\ Sohrab Kazemi \\ Babol University of Medical Sciences
}

Ali Akbar Moghadamnia ( $\nabla$ aliamoghadamnia@gmail.com )

Babol University of Medical Sciences

\section{Research Article}

Keywords: Propolis, Fluorouracil, Neoplasms, Myocardial Infarction

Posted Date: March 17th, 2022

DOI: https://doi.org/10.21203/rs.3.rs-1359440/v2

License: (c) (i) This work is licensed under a Creative Commons Attribution 4.0 International License.

Read Full License 


\section{Abstract \\ Background}

5- Fluorouracil (5-FU) is one of the most common chemotherapeutic agents used in treating solid tumors, and the 5-FU-induced cardiotoxicity is the second cause of cardiotoxicity induced by chemotherapeutic drugs. Propolis (Pro) has vigorous anti-inflammatory activity. Its cardio-protective characteristic against doxorubicin-induced cardiotoxicity was previously proven. The current study aimed to appraise the effect of Pro on 5-FU-induced cardiotoxicity in rats.

\section{Methods}

Twenty-four male Wistar rats were divided into four groups: Control, 5-FU, 5-FU + Pro $250 \mathrm{mg} / \mathrm{kg}$, and 5$\mathrm{FU}+$ Colchicine (CLC) $5 \mathrm{mg} / \mathrm{kg}$. Different hematological, serological, biochemical, histopathological, and molecular assays were performed to assess the study aim. Moreover, rat myocardium ( $\mathrm{H} 9 \mathrm{C} 2(2-1))$ and human skin fibroblast (HNFF-P18) cell lines were also used to assess this protective effect in-vitro.

\section{Results}

5-FU resulted in significant cardiotoxicity represented by an increase in malondialdehyde (MDA) levels, cyclooxygenase-2 (COX-2), and tumor necrosis factor-a (TNF-a) expression, cardiac enzyme levels, and histopathological degenerations. 5-FU treatment also decreased bodyweight, total anti-oxidant capacity (TAC), catalase (CAT) levels, blood cell counts, and hemoglobin $(\mathrm{Hb})$ levels. In addition, 5-FU disrupted ECG parameters, including increased elevation in the ST-segment and increased QRS complex and QTC duration. Treating with Pro reduced oxidative stress, cardiac enzymes, histopathological degenerations, and COX-2 expression in cardiac tissue alleviated ECG disturbances and increased the number of blood cells and TAC levels. Moreover, 5-FU-induced bodyweight loss was ameliorated after treatment with Pro.

\section{Conclusion}

Our results demonstrated that treatment with Pro significantly improved cardiotoxicity induced by 5-FU in rats.

\section{Introduction}

Cardiovascular diseases (CVDs) are a significant cause of death globally and substantially burden countries. In 2015, about 18 million deaths worldwide were due to CVDs, half of which were caused by ischemic heart disease (IHD) ${ }^{1}$. It has been proven that atherosclerosis is one of the significant risk factors for coronary artery disease (CAD), and in turn, inflammation has also been proven to play a vital 
role in the manifestation of atherosclerosis ${ }^{2}$. Thus, several chemotherapeutic agents, by inducing inflammation and subsequent inflammatory response in the body, can cause severe cardiotoxicity, including myocardial ischemia ${ }^{3}$. Angiogenic inhibitors, such as bevacizumab ${ }^{4}$, sunitinib, and sorafenib ${ }^{5}$, and also direct $A B L$ inhibitors, including imatinib ${ }^{6}$ and dasatinib ${ }^{7}$, can cause myocardial ischemia. Other essential and widely-used chemotherapeutic drugs with cardiotoxicity side effects are doxorubicin ${ }^{8}$ and 5 -FU ${ }^{9}$.

5-fluorouracil (5-FU), a member of the fluoropyrimidine class of chemotherapeutic drugs, can cease DNA replication by inhibiting the formation of thymidine by several intracellular mechanisms, of which inhibition of thymidylate synthase enzyme seems to play the significant role ${ }^{10}$. Since its introduction in 1957 by Heidelberger et al. ${ }^{11}$, it has been an essential part of chemotherapy regimens for several solid tumors, including gastrointestinal, breast, head and neck, and pancreatic neoplasms ${ }^{12}$. It can cause many side effects, including severe cardiotoxicity, often manifested as myocardial ischemia, but can also be presented as cardiac arrhythmias, hyper- and hypotension, left ventricular dysfunction, cardiac arrest, and even death ${ }^{13}$. The prevalence of 5 -FU-induced cardiac complications can vary between $0-20 \%$, mostly depending on the dosage, comorbidity factors, and schedule of the chemotherapy regimen ${ }^{9}$. The definite mechanisms of 5-FU-induced cardiotoxicity are not clearly understood. However, some studies suggest that coronary artery thrombosis, arteritis, or vasospasm may be responsible for its adverse effects ${ }^{13}$. Other mechanisms have also been reported to be responsible for this drug's cardiotoxicity, including direct myocardial toxicity ${ }^{14}$, activation of autoimmune responses ${ }^{15}$, and direct coronary endothelial intima toxicity ${ }^{16}$. Several known polyphenols have proven cardio-protective characteristics, including resveratrol ${ }^{17}$, quercetin ${ }^{18}$, catechins ${ }^{19}$, curcumin ${ }^{20}$, baicalein ${ }^{21}$, genistein ${ }^{22}$, and apigenin ${ }^{23}$. Also, propolis is another agent with proven cardioprotective effects ${ }^{24}$.

Propolis, also known as bee glue, is a lipophilic resinous agent that honey bees produce while constructing their hives. Briefly, bees collect different botanical materials, such as mucilage, gums, resins, and lattices. When these materials mix with the enzyme $\beta$-glycosidase secreted in bees' saliva, they undergo partial digestion, and when added to beeswax, they eventually form raw propolis known as propolis in nature ${ }^{25}$. The nature of this final product alters in different temperatures so that it becomes hard and wax-like when cool but soft and sticky when warm. Components of Propolis, and as a result, its biological activities, can vary widely based on where it is made and the plant variability around the hive 25 . It can be made mainly of phenolics, like flavonoids, aromatic acids, and their ester in temperate regions, to prenylated $p$-coumaric acid derivatives in Brazilian propolis ${ }^{25}$. Some of its proven biological activities include: anti-inflammatory, anti-oxidant, anti-ulcerogenic, hepatoprotective ${ }^{26}$, antitumor ${ }^{27}$, immune-stimulation/modulation ${ }^{28}$, antibacterial ${ }^{29}$, antiviral ${ }^{30}$, antifungal ${ }^{31}$, and anti-parasite ${ }^{32}$. Its cardio-protective characteristic against doxorubicin- ${ }^{24}$, hypothermic- ${ }^{33}, \mathrm{~N} \omega$-nitro-L-arginine methyl ester (L-NAME)-induced cardiotoxicity ${ }^{34}$ has also been previously investigated. 
This study aims to investigate the ameliorative effects of propolis administration in 5-fluorouracilinduced cardiotoxicity in-vitro and in-vivo.

\section{Materials And Methods \\ 2.1. Chemicals}

All chemicals were of the highest grade (analytical grade). N-hexane (HPLC grade), ethanol (purity $>98 \%$ ), $\mathrm{N}, \mathrm{O}-\mathrm{Bis}$ (trimethylsilyl)trifluoroacetamide (BSTFA) with 1\% trimethylsilyl chloride (TMCS), polyethylene glycol ( $\left.M_{n}: 6000\right)$, and castor oil were purchased from Merck KGaA, Darmstadt, Germany. Dimethyl sulfoxide (DMSO, GC grade, purity > 99.99\%) was acquired from Sigma-Aldrich Co., St. Louis, MO, USA. 5fluorouracil $1000 \mathrm{mg}$ vial was purchased from Iran Darou, Tehran, Iran. Ultrapure Milli-Q water (18.2 MW) was used in all experiments.

\subsection{Propolis origin and collection}

Apis mellifera bee hives' crude propolis were collected in Spring 2020 in the Alborz mountains in Polur, Tehran, Iran. All propolis samples were kept at $4^{\circ} \mathrm{C}$ protected from light until further extract preparation.

\subsection{Propolis extraction}

Propolis ethanolic extract was prepared according to a previous study ${ }^{35}$. Briefly, after being powdered by mortar and pestle, propolis samples were dissolved in n-hexane with a 3:100 ratio (w/v), meaning 3 grams of crude propolis were dissolved in $100 \mathrm{~mL}$ of the solvent. Then, after shaking at $240 \mathrm{rpm}$ at room temperature for three days, the bee wax was removed after filtering the mixture with Whatman grade 42 ashless quantitative filter papers (Sigma-Aldrich Co., St. Louis, MO, USA) and drying the remaining solid parts of the mixture on the filter at room temperature. These residues were then dissolved in $70 \%$ ethanol with a 3:10 ratio $(\mathrm{w} / \mathrm{v})$. The resulting mixture again was filtered by Whatman grade 42 ashless quantitative filter papers under vacuum. Then, the organic solvent was removed with a rotatory evaporator at $50^{\circ} \mathrm{C}$. For further analysis, the final product was stored at $4^{\circ} \mathrm{C}$, away from direct light.

\subsection{Derivatization procedure}

Five grams of the final Propolis ethanolic extract were dissolved in $250 \mu \mathrm{L}$ of pyridine (anhydrous, purity $=99.8 \%$ ) and $500 \mu \mathrm{L}$ of BSTFA, including $1 \%$ TMCS, and shook at $100^{\circ} \mathrm{C}$ for half an hour.

\subsection{Gas chromatography-mass spectrometry (GC-MS) analysis of propolis ethanolic extract}

The chemical composition of Propolis ethanolic extract was assessed using a gas chromatography-mass spectrometry device (5977B GC/MSD, Agilent, Santa Clara, CA, USA). The DB-5ms capillary column experimental conditions were as follows: length $=30 \mathrm{~m}$, inner diameter $=0.25 \mathrm{~mm}$, film thickness $=0.25$ $\mu \mathrm{m}$, gas carrier: Helium with purity $\geq 99.9995 \%$ (Sigma-Aldrich Co., St. Louis, MO, USA), gas flow rate: 1 $\mathrm{mL} / \mathrm{min}$. The GC-MS analysis was based on a previous study ${ }^{36}$. Briefly, $1 \mu \mathrm{L}$ of the final solution 
prepared in the last step was injected into the device with an autosampler in a split 10:1 ratio. The temperature of the injector was set at $250^{\circ} \mathrm{C}$. The oven temperature was programmed to start from $50^{\circ} \mathrm{C}$ (storage time of $1 \mathrm{~min}$ ), then increasing $8^{\circ} \mathrm{C} / \mathrm{min}$ rate up to $120^{\circ} \mathrm{C}$ (storage time of $1 \mathrm{~min}$ ). Finally, the temperature was to increment at a $6^{\circ} \mathrm{C} / \mathrm{min}$ rate up to $250^{\circ} \mathrm{C}$ in about 15 minutes. The total device running time was 47 minutes, with a solvent delay of $0-3$ minutes. The propolis sample components' names, molecular weight, and structure were identified using the National Institute of Standards and Technology (NIST 11 Variant) database.

\subsection{Cell cultures}

Rat myocardium (H9C2(2 - 1)) cell line was obtained from the National Cell Bank of Iran (NCBI, Pasteur Institute, Tehran, Iran). These cell lines were cultured in Roswell Park Memorial Institute medium (RPMI 1640) containing glucose $2 \mathrm{~g} / \mathrm{L}$, L-arginine, and L-glutamine 200 and $300 \mathrm{mg} / \mathrm{L}$, respectively, supplemented with $10 \%$ fetal bovine serum (FBS) and $1 \%$ pen/strep comprising of penicillin $\mathrm{G} 100 \mathrm{U} / \mathrm{mL}$, and streptomycin $100 \mu \mathrm{g} / \mathrm{mL}$. The cell lines were grown as monolayers in $25 \mathrm{~cm}^{2}$ cell culture flasks at $37^{\circ} \mathrm{C}$ in a $5 \% \mathrm{CO}_{2}$ humidified atmosphere.

\subsection{Cell viability assay}

The cytotoxicity of Propolis ethanolic extract was assessed with the cell viability (MTT) assay. The method for MTT assay used in this study was described elsewhere ${ }^{37}$. Briefly, the mentioned cell lines were treated with 5-FU $75 \mu \mathrm{M}, \mathrm{CLC} 50 \mu \mathrm{g} / \mathrm{mL}$, and Pro 50,100 , and $200 \mu \mathrm{g} / \mathrm{mL}$, with each concentration being investigated in triplicates. The treated plates were then incubated at $37^{\circ} \mathrm{C}$ in a $5 \% \mathrm{CO}_{2}$ humidified atmosphere, and after 48 hours, an MTT assay was performed. Then, $5 \mathrm{mg} / \mathrm{mL}$ concentration of MTT dye (Alfa Aesar, Thermo Fisher (Kandel) GmbH, Kandel, Germany) was mixed with phosphate-buffered saline (PBS), the mixture was filtered by Whatman grade 42 ashless quantitative filter papers (SigmaAldrich Co., St. Louis, MO, USA), and $50 \mu \mathrm{L}$ of the filtered solution was added to each seeded well and incubated at $37^{\circ} \mathrm{C}$ for 4 hours. After removing the supernatant, $150 \mu \mathrm{L}$ of DMSO was added to each well, and the optical density (OD) was measured by an absorbance microplate reader (ELx808, BioTek, Winooski, VT, United States) at $570 \mathrm{~nm}$.

\subsection{Animal experimental design}

Twenty-four male Wistar rats (6-8 weeks, $180 \pm 20 \mathrm{~g}$ ) were obtained from Babol University of Medical Sciences' laboratory animal facility. All animals were kept in 12-hour light 12-hour dark cycles and housed in a controlled environment with specified temperature $\left(22-24^{\circ} \mathrm{C}\right)$ and humidity $(50 \pm 5 \%)$. Animals were kept in cages with LSB Aspen woodchip bedding and had free access to food and tap water during the whole experimental period. All study procedures were conducted following the approval of the National Institute for Medical Research Development (NIMAD) ethical board (Code: IR.NIMAD.REC.1399.255).

Study rats were randomly divided into four groups as follows:

a. The negative Control group received $200 \mu \mathrm{L}$ of castor oil for 14 days (Control). 
b. The 5-fluorouracil group received a bolus $125 \mathrm{mg} / \mathrm{kg}$ dosage of 5-fluorouracil intraperitoneally (5-FU). c. The experimental group received a bolus $125 \mathrm{mg} / \mathrm{kg}$ dosage of 5-fluorouracil intraperitoneally plus propolis ethanolic extract $250 \mathrm{mg} / \mathrm{kg} / \mathrm{d}$ by oral gavage for 14 days (5-FU + Pro).

d. The positive control group received a bolus $125 \mathrm{mg} / \mathrm{kg}$ dosage of 5 -fluorouracil intraperitoneally plus colchicine $5 \mathrm{mg} / \mathrm{kg} / \mathrm{d}$ by oral gavage for 14 days (5-FU + CLC).

\subsection{The electrocardiography (ECG)}

Electrocardiography (ECG) was performed for 15 minutes the day before euthanizing the study animals. For this purpose, the rats in each group were anesthetized with ketamine/xylazine, subcutaneous peripheral limb electrodes were inserted into the limbs to record the standard lead II of the electrocardiograph, and ECG parameters, such as ST-segment elevation and QRS and QTc duration, were measured using an ECG device (eLab, Sciencebeam, Tehran, Iran) ${ }^{38}$.

\subsection{Sample collection and preparation}

Rats were weighed and anesthetized with ketamine/xylazine on the fifteenth day. Then, $5 \mathrm{~mL}$ blood samples were immediately collected directly from the heart and poured into $5 \mathrm{~mL}$ microtubes for further serum separation by centrifugation for 15 minutes at $1,500 \mathrm{~g}$. Afterward, the animals were euthanized by the decapitation method, and their heart was harvested. About $20-30 \mathrm{mg}$ of the harvested heart tissue were immediately transferred to $1.5 \mathrm{~mL}$ RNase and DNase-free microtubes, including $200 \mu \mathrm{L}$ RNA later solution (Yekta Tajhiz Azma, Tehran, Iran). After overnight incubation at $4^{\circ} \mathrm{C}$, these microtubes were transferred to $-80^{\circ} \mathrm{C}$ until the RNA extraction. However, the remaining tissue samples were placed in a formalin-containing tube, and then along with serum samples, were kept at $-20^{\circ} \mathrm{C}$ for further analysis.

\subsection{Laboratory analysis}

\subsubsection{Complete blood count (CBC)}

The white blood cells $\left(\mathrm{WBC}, \times 10^{3} / \mu \mathrm{L}\right)$, and red blood cells $\left(\mathrm{RBC}, \times 10^{6} / \mu \mathrm{L}\right)$ count, hemoglobin $(\mathrm{Hb}, \mathrm{g} / \mathrm{dL})$, and platelets $\left(\mathrm{PLT}, \times 10^{3} / \mu \mathrm{L}\right)$ were quantified with an automated counter $(\mathrm{H} 9000$, Xuzhou forward medical instrument Co. Ltd., Xuzhou, China).

\subsubsection{Serological analysis}

As to determine the enzymatic activity of liver tissue, the levels of liver function tests (LFT), i.e., aspartate aminotransferase (AST) and alanine aminotransferase (ALT) were evaluated by commercial ELISA kits (Pars Azmun, Karaj, Iran). Then, De Ritis (AST/ALT) ratio was calculated for study samples.

\subsubsection{Cardiac marker enzymes assay}

Lactate dehydrogenase ( $\mathrm{LDH}, \mathrm{IU} / \mathrm{L})$ and creatinine kinase-MB (CK-MB, IU/L) activities were measured in serum samples by commercial ELISA kits (Pars Azmun, Karaj, Iran).

\subsection{Biochemical analysis}


A commercial enzyme-linked immunosorbent assay (ELISA) kit (Teb Pazhouhan Razi, Tehran, Iran) was used to assess the total anti-oxidant capacity (TAC) of the rats' serum samples. Miller et al. (1993) published a detailed description of the technique ${ }^{39}$. Finally, an absorbance microplate reader (ELx808, BioTek, Winooski, VT, United States) measured the OD of the samples at $420 \mathrm{~nm}$. This ELISA kit's intraand inter-assay coefficient of variation was $5.7 \%$ and $3.7 \%$, respectively, and its detection range was $45-$ $420 \mu \mathrm{M}$.

\subsubsection{Catalase (CAT) assay}

Catalase (CAT) is a ubiquitous anti-oxidant enzyme present in all cells' peroxisomes, providing cell protection against oxidative stress-induced damage by catalyzing the decomposition of hydrogen peroxide $\left(\mathrm{H}_{2} \mathrm{O}_{2}\right)$ to water and oxygen. A commercial ELISA kit was used to assess CAT levels (Teb Pazhouhan Razi, Tehran, Iran) in which CAT activity was assessed by the reaction of the CAT present in the sample with methanol in the presence of an optimal concentration of $\mathrm{H}_{2} \mathrm{O}_{2}$ to produce formaldehyde. After adding a chromogen that turns aldehydes purple, formaldehyde formation is determined by colorimetric analysis. Finally, an absorbance microplate reader (ELx808, BioTek, Winooski, VT, United States) measured the OD of the samples at $540 \mathrm{~nm}$. This kit's intra- and inter-assay coefficient of variation was $4.1 \%$ and $9.9 \%$, respectively.

\subsubsection{Malondialdehyde (MDA) assay}

Malondialdehyde (MDA) assay was used to evaluate the lipid peroxidation levels of the serum samples. MDA is an end product of the oxidative decomposition of the polyunsaturated fatty acids initiated by free radicals. Thus, it is a frequently measured biomarker of oxidative stress. A commercial ELISA kit was used to assess MDA levels (Teb Pazhouhan Razi, Tehran, Iran) using a spectrophotometric method based on the reaction between MDA and thiobarbituric acid (TBA) generating an MDA-TBA adduct, which can be quantified by colorimetric analysis. Finally, an absorbance microplate reader (ELx808, BioTek, Winooski, VT, United States) measured the OD of the samples at $540 \mathrm{~nm}$. This ELISA kit's intra- and inter-assay coefficient of variation was $6.7 \%$ and $7.2 \%$, respectively, and its detection range was $0-50 \mu \mathrm{M}$.

\subsection{Histopathological analysis}

Each rats' heart was harvested and weighed separately. These tissue specimens were fixed in 10\% formalin solution and processed using a tissue processing device (dewatering, clearing, and staining), embedded in paraffin blocks, sliced in $5 \mu \mathrm{m}$ thicknesses layers, and stained with hematoxylin and eosin (H\&E). An average of four sections was placed on each slice. Therefore, approximately 390 sections were evaluated with digital light microscopy. Hyperemia, necrosis, and hyalinization were assessed in each section. An experienced user (Seyed Mohammad Hosseini) performed all morphological analysis using a Medicus pro-Myko microscope (Helmut Hund $\mathrm{GmbH}$, Wetzlar, Germany) under $\times 40, \times 100$, and $\times 400$ magnifications.

\subsection{RNA extraction}

A total RNA extraction commercial kit (Pars Tous Biotechnology, Mashhad, Iran) extracted the total RNA of the previously described 20-30 mg of harvested heart tissue. The extracted RNA of each sample was 
measured using a NanoDrop spectrophotometer (Thermo Scientific, Waltham, MA, USA). Then, all RNA samples were transferred to $-80^{\circ} \mathrm{C}$ until further analysis

\subsection{5 cDNA synthesis}

For cDNA synthesis, a commercial cDNA synthesis kit (Pars Tous Biotechnology, Mashhad, Iran) was used in which the following mixture was included: $250 \mathrm{ng}$ of the previously mentioned extracted RNA samples, $5 \mu \mathrm{L}$ of the $2 x$ enzyme buffer, and $1 \mu \mathrm{L}$ of the reverse transcriptase enzyme. The resulting mixture was then reached to a $10 \mu \mathrm{L}$ volume using diethylpyrocarbonate (DEPC)-treated water. Afterward, the mixture was incubated with a PCR-thermocycler (FlexCycler ${ }^{2}$, Analytik Jena AG, Jena, Germany) as follows: At room temperature for 10 minutes for the random hexamer primer annealing, at $47^{\circ} \mathrm{C}$ for 60 minutes for the reverse transcriptase reaction, and finally, at $85^{\circ} \mathrm{C}$ for 5 minutes for the ending the reaction.

\subsection{Quantitative real-time PCR}

cDNA samples were amplified in duplicates by PCR in RealQ Plus Master Mix Green (Ampliqon, Odense C, Denmark) using a 7300 Real-Time PCR System (Applied Biosystems, Thermo Fisher Scientific, Waltham, MA, USA). OLIGO Primer Analysis Software 7 (DBA Oligo, Inc., Colorado Springs, CO, USA) was used to design specific primers summarized in Table 1. Briefly, real-time PCR was performed using $10 \mu \mathrm{L}$ of PCR reaction mixture consisting of $6.25 \mu \mathrm{L}$ of master mix, $0.25 \mu \mathrm{L}$ of each primer, $2.25 \mu \mathrm{L}$ of RNase free $\mathrm{dH}_{2} \mathrm{O}$, and $1 \mu \mathrm{L}$ of cDNA templates. The amplification reaction cycles were performed as follows: Initial denaturation at $95^{\circ} \mathrm{C}$ for 15 minutes, then 40 cycles at $95^{\circ} \mathrm{C}$ for 15 seconds, annealing temperature for 30 seconds which was different for each primer as depicted in Table 1, and extension at $72^{\circ} \mathrm{C}$ for 30 seconds. At the end of the amplification cycles, the temperature of the samples was increased at a steady rate of $0.2^{\circ} \mathrm{C} / \mathrm{min}$ from $60^{\circ} \mathrm{C}$ to $95^{\circ} \mathrm{C}$ for calculating the melting curve. Melting curve analyses and negative controls were embedded in each assay to ensure that the reaction contamination was not producing anyCR products ${ }^{40}$. The target genes' relative expression ratios $(R)$ were measured using a model proposed by Pfaffl et al. ${ }^{41}$, in which the reference and target genes' efficiency was calculated according to a relative standard curve comprised of various dilutions (i.e., 1:1, 1:2, 1:4, 1:8, 1:16, and 1:32) of cDNAs from high-quality samples with good target genes expression. In this study, glyceraldehyde 3phosphate dehydrogenase (GAPDH) was used as the reference gene to normalize samples. 
Table 1

Primer sequences of COX-2, TNF- $a$, and the housekeeping

genes

\begin{tabular}{|ll|}
\hline Primer & $\mathbf{5}^{\prime \mathbf{-}} \mathbf{3}^{\prime}$ \\
\hline COX-2 forward & CAACCAGCAGTTCCAGTATCAGA \\
\hline COX-2 reverse & CAAGGAGGATGGAGTTGTTGTAGAG \\
\hline TNF-a forward & AAATGGGCTCCCTCTCATCAGTTC \\
\hline TNF-a reverse & TCTGCTTGGTGGTTTGCTACGAC \\
\hline GAPDH forward & CTACATGGCCTCCAAGGAGTAAG \\
\hline GAPDH reverse & CCTCCTCTTCTTCGTCTATGGC \\
\hline
\end{tabular}

\subsection{Statistical analysis}

All data were presented as mean \pm standard deviation (SD). One-way ANOVA followed by post hoc Tukey tests were used to assess differences between study groups. Moreover, for non-parametric analyses, such as histopathological evaluations, the Kruskal-Wallis and Mann-Whitney $\mathrm{U}$ tests were utilized. A probability level ( $p$-value) of $<0.05$ were considered statistically significant. Nevertheless, wherever applicable, other $p$-values are presented, i.e., $p<0.01,<0.001$, and $<0.0001$. All statistical analyses were performed with the SPSS v. 26 software (IBM Inc., Chicago, IL, USA).

\section{Results}

\subsection{The Gas chromatography-mass spectrometry (GC-MS)}

In the GC-MS study, the first peak detected at $32.066 \mathrm{~s}$ was related to the pinostrobin chalcone $(15.099 \%$ of total). The second, third, and fourth peaks were related to the galangin ( $55.509 \%$ of total, $33.256 \mathrm{~s})$, tectochrysin (13.216\% of total, $34.973 \mathrm{~s})$, and naringenin (16.177\% of total, $36.552 \mathrm{~s})$, respectively (Fig. 1).

\subsection{The cell viability (MTT) assay}

The highest and lowest levels of MTT were detected in the Control and 5-FU 75 + CLC 50 groups, respectively. The levels of the MTT were almost the same in DMSO and 5-FU $75+$ Pro 50 groups. The cell survivability in 5-FU 75 + CLC 50, 5-FU 75 + Pro 100 and 5-FU 75 + Pro 200 groups were significantly lower than the 5 -FU $75+$ Pro 50 group $(p<0.0001)$. Also, the MTT level in the Control group was significantly higher than the 5-FU $75+$ Pro 50 group $(p<0.0001)$. Moreover, it was observed that increasing concentrations of Pro would decrease the survivability of the cells in a dose-dependent manner, supposedly due to a synergistic toxic effect with 5-FU (Fig. 2).

\subsection{Relative heart weight of rats}


The highest and lowest values of relative heart weight were observed in the 5-FU + Pro and Control groups, respectively. The relative heart weight of study rats was significantly higher in the 5-FU + Pro group than the 5 -FU and Control groups $(p<0.001)$. Moreover, the relative heart weight in the 5 -FU and Control groups was lower than the 5-FU + CLC group, but these differences were insignificant. The relative heart weight of rats in the 5-FU + Pro group was higher than the 5-FU + CLC group, but this difference was also not significant (Fig. 3).

\subsection{The electrocardiography parameters 3.4.1. QRS interval}

The highest and lowest QRS intervals in the ECG examinations were measured in the 5-FU and 5-FU + Pro groups, respectively (Table 2). The QRS interval of the 5-FU and 5-FU + Pro groups was significantly higher than the Control group $(p<0.0001)$. Also, the QRS interval of the $5-F U+$ Pro and $5-F U+C L C$ groups was significantly lower than the 5-FU group $(p<0.0001)$. Moreover, the $5-\mathrm{FU}+$ Pro group had a shorter QRS interval than the 5-FU + CLC group $(p<0.0001)$ (Fig. 4).

Table 2

Electrocardiogram parameters of study groups

\begin{tabular}{|c|c|c|c|}
\hline \multirow[t]{2}{*}{ Study Groups } & \multicolumn{3}{|l|}{ ECG parameters } \\
\hline & QRS interval (ms) & ST-segment (mV) & QTc (ms) \\
\hline Control & $12.38 \pm 0.07$ & $250.00 \pm 22.21$ & $115.60 \pm 1.82$ \\
\hline $5-\mathrm{FU}$ & $14.82 \pm 0.20^{\star \star \star \star}$ & $457.80 \pm 3.44^{\star \star \star \star}$ & $142.60 \pm 1.95^{\star \star \star \star}$ \\
\hline 5-FU + Pro & $11.41 \pm 0.18^{\star \star \star \star}$ & $217.20 \pm 9.11^{* *}, \# \# \# \#, \$$ & $114.20 \pm 3.02^{\# \# \# \#, \$ \$ \$}$ \\
\hline 5-FU+ CLC & 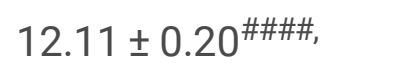 & $241.70 \pm 5.87^{\# \# \#, \$}$ & $106.80 \pm 3.11^{\star \star \star \star}, \# \# \#, \$ \$ \$$ \\
\hline
\end{tabular}

Values are expressed as mean \pm standard deviation (SD). Groups: Control, Normal saline; 5-FU, 5-FU 125 mg/kg; 5-FU + Pro, 5-FU 125 mg/kg + Propolis ethanolic extract 250 mg/kg/d; 5-FU + CLC, 5-FU 125 $\mathrm{mg} / \mathrm{kg}+$ Colchicine $5 \mathrm{mg} / \mathrm{kg} / \mathrm{d}^{* *}$, and ${ }^{* \star *}$ Indicate statistically significant difference compared to the control group ( $p<0.01$, and $p<0.0001$, respectively). \#\#\# Indicate statistically significant difference compared to the 5 -FU group $(p<0.0001)$. $\$$, $\$ \$$, and

Indicate statistically significant difference between the treatment groups $(p<0.05, p<0.001$, and $p<$ 0.0001 , respectively).

\subsubsection{ST-segment}

$\mathrm{n}$ the ECG examinations, the highest and lowest ST-segment was detected in the 5-FU and 5-FU + Pro groups, respectively (Table 2). The 5-FU and 5-FU + Pro groups' ST-segment was significantly higher than 
the Control group $(p<0.0001$, and $p<0.01$, respectively). Also, the 5-FU + Pro and 5-FU + CLC groups' STsegment were significantly less than the 5 -FU group $(p<0.0001)$. Moreover, the ST-segment in the 5 -FU + Pro group was significantly lower than the 5 -FU + CLC group $(p<0.05)$ (Fig. 4).

\subsubsection{QTC}

It was observed that the highest and lowest QTc belonged to the 5-FU and 5-FU + CLC groups, respectively (Table 2). The QTc of 5-FU and 5-FU + CLC groups were significantly higher and lower than the Control group, respectively $(p<0.0001)$. Also, the QTc of $5-F U+$ Pro and $5-F U+C L C$ groups were significantly lower than the 5-FU group $(p<0.0001)$. Moreover, the QTc was significantly higher in the 5-FU + Pro group than in the 5-FU + CLC group ( $p<0.001)$ (Fig. 4).

\subsection{The hematological parameters \\ 3.5.1. Complete blood count (CBC) \\ 3.5.1.1 White blood cell (WBC)}

The highest and lowest WBC counts belonged to the 5-FU + Pro and 5-FU groups, respectively. WBC was significantly higher in the 5-FU + Pro group than in the 5-FU group $(p<0.05)($ Table 3$)$.

Table 3

Hematological factors of study groups

\begin{tabular}{|c|c|c|c|c|c|c|c|}
\hline \multirow{2}{*}{$\begin{array}{l}\text { Study } \\
\text { Groups }\end{array}$} & \multicolumn{7}{|c|}{ Hematological factors } \\
\hline & $\begin{array}{l}\text { WBC, } x \\
10^{3} / \mu \mathrm{L}\end{array}$ & $\begin{array}{l}\text { RBC, } x \\
10^{6} / \mu \mathrm{L}\end{array}$ & $\begin{array}{l}\mathrm{Hb}, \\
\text { g/dL }\end{array}$ & $\mathrm{Plt}, \times 10^{3} / \mu \mathrm{L}$ & $\begin{array}{l}\text { AST/ALT } \\
\text { ratio }\end{array}$ & LDH, IU/L & $\begin{array}{l}\text { CKMB, } \\
\text { IU/L }\end{array}$ \\
\hline Control & $\begin{array}{l}9.75 \pm \\
2.24\end{array}$ & $\begin{array}{l}7.10 \pm \\
0.83\end{array}$ & $\begin{array}{l}13.97 \\
\pm 1.14\end{array}$ & $\begin{array}{l}643.83 \pm \\
202.03\end{array}$ & $\begin{array}{l}1.74 \pm \\
0.42\end{array}$ & $\begin{array}{l}1853.17 \pm \\
728.11\end{array}$ & $\begin{array}{l}68.67 \pm \\
30.79\end{array}$ \\
\hline 5-FU & $\begin{array}{l}8.16 \pm \\
3.49\end{array}$ & $\begin{array}{l}4.27 \pm \\
0.59^{\star \star \star}\end{array}$ & $\begin{array}{l}9.98 \pm \\
2.43^{\star \star}\end{array}$ & $\begin{array}{l}628.60 \pm \\
258.47\end{array}$ & 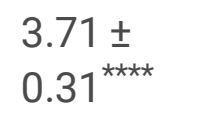 & $\begin{array}{l}2541.40 \pm \\
544.56\end{array}$ & $\begin{array}{l}102.60 \pm \\
14.99\end{array}$ \\
\hline $\begin{array}{l}5-F U+ \\
\text { Pro }\end{array}$ & $\begin{array}{l}22.48 \pm \\
14.05^{\#}\end{array}$ & $\begin{array}{l}5.24 \pm \\
0.58^{\star \star}\end{array}$ & $\begin{array}{l}11.10 \\
\pm 0.91^{*}\end{array}$ & $\begin{array}{l}1353.83 \pm \\
249.26^{\star \star \star}, \# \# \#\end{array}$ & $\begin{array}{l}2.89 \pm \\
0.52^{\star \star}, \#, \$\end{array}$ & $\begin{array}{l}2754.50 \pm \\
771.68\end{array}$ & $\begin{array}{l}105.50 \pm \\
61.26\end{array}$ \\
\hline $\begin{array}{l}\text { 5-FU+ } \\
\text { CLC }\end{array}$ & $\begin{array}{l}11.53 \pm \\
3.93\end{array}$ & $\begin{array}{l}6.22 \pm \\
1.26^{\#}\end{array}$ & $\begin{array}{l}10.63 \\
\pm 0.77^{*}\end{array}$ & $\begin{array}{l}932.50 \pm \\
297.09\end{array}$ & $\begin{array}{l}2.13 \pm \\
0.48^{\# \# \#, \$}\end{array}$ & $\begin{array}{l}1780.80 \pm \\
460.55\end{array}$ & $\begin{array}{l}53.00 \pm \\
12.02\end{array}$ \\
\hline
\end{tabular}

Values are expressed as mean \pm standard deviation (SD). Groups: Control, Normal saline; 5-FU, 5-FU 125 mg/kg; 5-FU + Pro, 5-FU 125 mg/kg + Propolis ethanolic extract 250 mg/kg/d; 5-FU + CLC, 5-FU 125 $\mathrm{mg} / \mathrm{kg}+$ Colchicine $5 \mathrm{mg} / \mathrm{kg} / \mathrm{d}^{*}{ }^{* *},{ }^{* * *}$, and ${ }^{* \star * *}$ Indicate statistically significant difference compared to the control group ( $p<0.05, p<0.01, p<0.001$, and $p<0.0001$, respectively). \#, and ${ }^{\# \# \# ~ I n d i c a t e ~ s t a t i s t i c a l l y ~}$ significant difference compared to the 5 -FU group ( $p<0.05$, and $p<0.001$, respectively). $\$$ Indicate statistically significant difference between the treatment groups $(p<0.05)$. 


\subsubsection{Red blood cell (RBC)}

The highest and lowest RBC counts were observed in the Control and 5-FU groups, respectively. The 5-FU + Pro and 5-FU groups' RBC counts were significantly lower than the Control group, respectively $(p<0.01$, and $p<0.001)$. Also, the RBC count of the $5-\mathrm{FU}+\mathrm{CLC}$ group was significantly higher than the $5-\mathrm{FU}$ group $(p<0.05)$ (Table 3$)$.

\subsubsection{Hemoglobin $(\mathrm{Hb})$}

The highest and lowest $\mathrm{Hb}$ levels were observed in the Control and 5-FU groups, respectively. The $\mathrm{Hb}$ level of the 5-FU + CLC, 5-FU + Pro, and 5-FU groups were significantly lower than the Control group $(p<0.05, p$ $<0.05$, and $p<0.01$, respectively) (Table 3 ).

\subsubsection{Platelet (PIt)}

The highest and lowest Plt counts were observed in the 5-FU + Pro and 5-FU groups, respectively. The Plt counts of the Control and 5-FU groups were significantly lower than the 5-FU + Pro group $(p<0.001)$ (Table 3).

\subsubsection{Serological analysis}

\subsubsection{AST/ALT ratio}

The highest and lowest AST/ALT ratio were observed in the 5-FU and Control groups, respectively (Fig. 5). This ratio was significantly higher in the 5 -FU and 5-FU + Pro groups than the Control groups $(p<0.0001$ and $p<0.01$, respectively). This difference was also observed when comparing the 5-FU + Pro and 5-FU+ CLC groups to the 5 -FU group ( $p<0.05$ and $p<0.001$, respectively). A significant difference was also observed between the treatment groups (Table 3).

\subsubsection{Cardiac marker enzymes assay 3.5.3.1 Lactate dehydrogenase (LDH)}

The highest and lowest LDH levels were observed in 5-FU + Pro and 5-FU + CLC groups, respectively. None of the groups had a significant difference from each other (Table 3).

\subsubsection{Creatinine kinase-MB (CK-MB)}

The highest and lowest CK-MB levels were observed in 5-FU + Pro and 5-FU + CLC groups, respectively. None of the groups had a significant difference from each other (Table 3).

\subsection{Biochemical analysis}

\subsubsection{Total anti-oxidant capacity (TAC) assay}


In the TAC analysis, the highest and lowest levels of anti-oxidants were measured in the Control and 5-FU groups, respectively, with the Control group significantly higher than the 5-FU group $(p<0.0001)$. The TAC level in the 5-FU + CLC group was slightly lower than that of the 5-FU + Pro group. Also, the TAC level in the 5 -FU + Pro and 5-FU + CLC groups was significantly higher than the 5-FU group $(p<0.0001)$ (Fig. 6A).

\subsubsection{Catalase (CAT) activity assay}

In the CAT activity assay, the highest and lowest levels of CAT activity were measured in the Control and 5 -FU groups, respectively, with the Control group significantly higher than the 5 -FU group $(p<0.001)$. CAT activity was almost equal in 5-FU + CLC and 5-FU + Pro groups, and it was significantly lower than the 5FU group $(p<0.01)$ (Fig. 6B).

\subsubsection{Malondialdehyde (MDA) assay}

In the MDA assay, the highest and lowest oxidant levels were measured in the 5-FU and Control groups, respectively, with the 5 -FU group significantly higher than the Control group $(p<0.01)$. Also, the MDA level in the 5-FU + CLC group were significantly lower than 5-FU $(p<0.05)$. Moreover, the MDA level in the 5-FU + Pro group was slightly higher than in the 5 -FU + CLC group (Fig. 6C).

\subsection{The histopathological changes of heart tissue}

\subsubsection{Necrosis}

In the study performed on heart tissue samples, the highest and lowest necrosis were observed in 5-FU and Control groups, respectively. The 5-FU + CLC, 5-FU + Pro, and 5-FU groups were significantly more necrotic than the Control group ( $p<0.01, p<0.01$, and $p<0.001$, respectively) (Table 4) (Fig. 7).

Table 4

Histopathological parameters of study groups

\begin{tabular}{|llll|}
\hline Study Groups & \multicolumn{3}{l}{ Histopathological parameters } \\
\cline { 2 - 4 } & Necrosis & Hyperemia & Hyalinization \\
\hline Control & $9.65 \pm 0.32$ & $8.00 \pm 0.0$ & $10.80 \pm 0.32$ \\
\hline 5-FU & $29.20 \pm 0.85^{\star \star \star}$ & $29.75 \pm 0.82^{\star \star \star *}$ & $25.70 \pm 0.67^{\star \star}$ \\
\hline 5-FU+Pro & $22.40 \pm 0.57^{\star *}$ & $16.50 \pm 0.68^{\star *}, \# \#, \$ \$$ & $22.75 \pm 0.63^{\star \star}$ \\
\hline 5-FU+CLC & $20.75 \pm 0.63^{\star *}$ & $27.75 \pm 0.92^{\star \star \star *}, \$ \$$ & $22.75 \pm 0.63^{\star \star}$ \\
\hline
\end{tabular}

Values are expressed as mean \pm standard deviation (SD). Groups: Control, Normal saline; 5-FU, 5-FU 125 mg/kg; 5-FU + Pro, 5-FU 125 mg/kg + Propolis ethanolic extract 250 mg/kg/d; 5-FU + CLC, 5-FU 125 $\mathrm{mg} / \mathrm{kg}+$ Colchicine $5 \mathrm{mg} / \mathrm{kg} / \mathrm{d} .{ }^{* *},{ }^{* \star *}$, and ${ }^{* \star *}$ Indicate statistically significant difference compared to the control group ( $<<0.01, p<0.001$, and $p<0.0001$, respectively). ${ }^{\# \#}$ Indicate statistically significant 
difference compared to the 5 -FU group $(p<0.01)$. \$ Indicate statistically significant difference between the treatment groups $(p<0.01)$.

\subsubsection{Hyperemia}

The highest and lowest rates of hyperemia were observed in the 5-FU and Control groups, respectively. The 5-FU + Pro, 5-FU + CLC, and 5-FU groups were significantly more hyperemic than the Control group ( $p$ $<0.01, p<0.0001$, and $p<0.0001$, respectively). Also, the hyperemia in the 5-FU and 5-FU + CLC groups were significantly higher than the 5-FU + Pro group $(p<0.01)$ (Table 4) (Fig. 7).

\subsubsection{Hyalinization}

The highest and lowest hyalinization were observed in the 5-FU and Control groups, respectively. The 5FU + CLC, 5-FU + Pro, and 5-FU groups were significantly more hyalinized than the Control group $(p<0.01)$ (Table 4) (Fig. 7).

\subsection{Gene expression \\ 3.8.1. TNF-a expression}

The lowest and highest levels of TNF-a expression were observed in the Control and 5-FU groups, respectively. TNF- $a$ expression was not significantly different in any group. Also, TNF- $a$ expression in the 5 -FU + CLC group was higher than in the 5-FU + Pro group (Fig. 8A).

\subsubsection{COX-2 expression}

The highest COX-2 expression was observed in the 5-FU group and the lowest in the Control group. Its expression was significantly lower in the Control group than in the 5-FU group $(p<0.01)$. COX-2 expression is higher in the 5-FU + CLC group than in the 5-FU + Pro group (Fig. 8B).

\section{Discussion}

Propolis is a resin produced by bees from various plants with different properties, such as anticancer, anti-inflammatory, antibacterial, and anti-oxidant, with no known serious side effects. This natural agent mainly exerts its effects by inhibiting mitochondrial stress, cell proliferation, and growth, stimulating cell cycle arrest, and inducing apoptosis ${ }^{42}$.

The MTT results showed that propolis was beneficial for rats treated with 5-FU in a dose-dependent manner. Nevertheless, as the propolis dose increased, its positive effect was diminished due to a synergistic toxic effect between the 5-FU and propolis itself. In a study, the cytotoxic effect of isorhamnetin on various gastric cancer cells was investigated. The study results showed that, depending on the time and dose of treatment, isorhamnetin could inhibit two multidrug-resistant gastric cancer cell lines and greatly increase the susceptibility of gastric tumor cells to chemotherapy ${ }^{43}$. Another study 
found that concomitant use of apigenin and 5-FU could decrease the viability of colorectal cancer cells 44

In this study, we examined the relative weight of rats' heart tissues. The results showed that the highest weight was observed in the 5-FU + Pro group, and the lowest was observed in the 5-FU group. The results showed that the decrease in the relative heart weight due to the use of 5-FU could be greatly compensated by propolis administration. However, CLC did not significantly differ in relative heart weight compared to the Control group. One study concluded that using silymarin, an anticancer flavonoid, prevented total body weight loss by reducing the peroxidative activity of doxorubicin ${ }^{45}$. The results of other studies also demonstrated that 5-FU administration would reduce' bodyweight, which could be due to damage to the liver ${ }^{46}$ or intestines tissues ${ }^{47}$.

In the ECG monitoring of study samples, it was deduced that using 5-FU significantly altered the ECG components compared to the Control group. These changes include QRS interval prolongation, STsegment elevation, and QTc increment. The use of propolis could greatly these changes to normal levels. The use of CLC also had a positive effect and returned these changes to normal levels. In a study, Aygun et al. ${ }^{48}$ showed that doxorubicin reduced $\mathrm{P}$ and QRS wavelengths, prolonged QT interval, and elevated ST segment. A study on fluoropyrimidines found that they exert a toxic effect on the heart muscle, depending on the dose and type of drug. For example, 5-FU at a lower dose had a more toxic effect on the myocardium than capecitabine ${ }^{13}$.

In our study, the number of blood cells and hemoglobin in the 5-FU group was lower than in other groups. The concomitant use of propolis largely compensated for this discrepancy. CLC is also effective in improving blood cell counts and hemoglobin levels to a large extent, similar to that of propolis. It has previously been observed that propolis can significantly increase the number of blood cells ${ }^{49}$. In a study of metrifonate toxicity, it was found that blood cell counts were greatly reduced, and concomitant use of propolis improved and largely compensated for the negative changes in hematologic parameters ${ }^{50}$.

Cardiac and serological biomarkers were also examined, and the results showed a significant increase in AST/ALT ratio and LDH and CKMB levels in the 5-FU group. Although concomitant administration of propolis could scarcely alleviate this negative impact, the use of CLC returned the level of these biomarkers nearly to normal values. A study showed that propolis containing chrysin could reduce and normalize the cardiac biomarkers increment induced by methotrexate ${ }^{51}$. Furthermore, elevated cardiac and serological biomarkers in the doxorubicin-treated rats were greatly reduced when propolis was simultaneously administered ${ }^{24}$. A study on reducing the toxicity of doxorubicin with pinocembrin, a flavonoid containing propolis, showed similar results, normalizing the cardiac biomarkers ${ }^{52}$. Regarding the AST/ALT ratio, which was almost doubled in our study in the 5-FU group compared to the Control group, there is growing evidence supporting this hypothesis that AST/ALT ratio would increase in cardiac events, especially ST-elevation MI (STEMI) ${ }^{53,54}$. s 
Catalase, an anti-oxidant enzyme, is a catalyst for the breakdown of $\mathrm{H}_{2} \mathrm{O}_{2}$ into water and oxygen, preventing oxidative stress-induced cell damage ${ }^{55}$. MDA is a measurable biomarker obtained by decomposing unsaturated fatty acids into free radicals ${ }^{37}$. This study observed that the increase in MDA level in the 5-FU group could be significantly counterbalanced and reduced by administering Propolis and CLC. Moreover, a decrease in the CAT and TAC levels was observed in the 5-FU group compared to the Control group, counterbalanced when propolis and CLC were administered to the treatment groups. In a study, the use of doxorubicin increased MDA production and peroxidative damage in treated rats, while concomitant use of propolis reduced MDA and peroxidative damage to rat mitochondria ${ }^{56}$. In another study on the effect of propolis in reducing oxidative stress induced by gentamicin, it was observed that the levels of hepatic and renal oxidative stress markers, such as CAT, and MDA, were significantly decreased and increased, respectively, when propolis was applied to the study samples ${ }^{57}$.

Histological alterations of the heart tissue samples were studied for necrosis, hyperemia, and hyalinization. The highest incidence of necrosis, hyperemia, and hyalinization was observed in the 5-FU group. However, simultaneous use of propolis or CLC could not significantly improve this destruction. A previous study found that 5-FU-induced cardiac toxicity was widespread in study animals and included multifocal myofiber necroses, vascular and valve changes, multiple myocardial interstitial hemorrhages, pericarditis, especially in the left ventricle, and inflammatory responses ${ }^{58}$. In histological studies performed by Gelen et al. ${ }^{59}$, necrosis and hyperemia in the kidney and vascular tissue of the group treated with 5-FU were immensely presented. On the other hand, concomitant use of hesperidin or curcumin (more effective than hesperidin) with 5-FU in other groups reduced the extent of these tissue changes ${ }^{59}$.

In the molecular analysis performed in this study, the expression of TNF- $a$ and COX-2 in the 5-FU group was increased compared to the Control group. With the use of propolis or CLC, the expression of COX-2 was significantly reduced, but yet higher than the Control group. Nonetheless, administration of propolis or CLC had little effect on TNF- $a$ expression, with slightly decreasing it. A study on the effect of capecitabine in the treatment of gastric cancer showed that this medication could increase the expression of the COX-2, which is greatly reduced by the concomitant use of isorhamnetin ${ }^{43}$. A systematic review demonstrated that following propolis use, serum levels of TNF- $a$ and CRP were significantly reduced ${ }^{60}$. Moreover, consumption of 5-FU significantly upregulated COX-2 expression, but simultaneous treatment with propolis counterbalanced and downregulated its expression in a dosedependent manner ${ }^{42}$.

\section{Conclusion}

Although the findings of this study should be validated in future preclinical and clinical studies, our results implied that the administration of propolis ethanolic extract could significantly ameliorate the destructive and cardiotoxic effects of chemotherapeutic medications, including 5-fluorouracil. Moreover, 
this beneficial effect was observed to be more potent than colchicine, which is an approved cardioprotective drug.

\section{Declarations}

\section{Funding}

The authors would like to thank the National Institute for Medical Research Development (NIMAD) for funding this study (Grant No.: 995714).

\section{Availability of data and materials}

The datasets used and/or analyzed during the current study are available from the corresponding author on reasonable request.

\section{Consent for publication}

Not applicable

\section{Acknowledgments}

The authors thank Mr. Mostafa Sheykhzadeh for assisting with the animal study.

\section{Competing interests}

Terence T. Sio reports that he provides strategic and scientific recommendations as a member of the Advisory Board and speaker for Novocure, Inc. and also as a member of the Advisory Board to Galera Therapeutics, which are not in any way associated with the content or disease site as presented in this manuscript. All other authors have no relevant financial interests to be declared.

\section{Ethics approval and consent to participate}

Animal used in the following investigation was handled strictly according to the Animal (Scientific Procedures) Act 1986. Moreover, all study procedures were conducted following the approval of the National Institute for Medical Research Development (NIMAD) ethical committee (Code: IR.NIMAD.REC.1399.255). Moreover, this study is reported in accordance with ARRIVE guidelines (https://arriveguidelines.org/).

\section{Authors' contributions}

- MB: Data collection, manuscript writing, and data analysis and visualization.

- RH: Helped with manuscript writing and study conduct.

- JJL: helped with manuscript writing and contributed substantial revisions to the manuscript's content. 
- RM: Visualization, software, and helped with manuscript writing.

- TTS: helped with manuscript writing and contributed substantial revisions to the manuscript's content.

- MH: Data collection and manuscript writing.

- SK: Design of the research study, data collection, and manuscript writing.

- AAM: Design of the research study and supervision.

All authors read and approved the final manuscript

\section{References}

1. Roth GA, Johnson C, Abajobir A, et al. Global, Regional, and National Burden of Cardiovascular Diseases for 10 Causes, 1990 to 2015. Journal of the American College of Cardiology. 2017;70(1):125. doi:10.1016/j.jacc.2017.04.052

2. Hansson GK. Inflammation, Atherosclerosis, and Coronary Artery Disease. New England Journal of Medicine. 2005;352(16):1685-1695. doi:10.1056/NEJMra043430

3. Maurea N, Coppola C, Piscopo G, et al. Pathophysiology of cardiotoxicity from target therapy and angiogenesis inhibitors. Journal of Cardiovascular Medicine. 2016;17:e19-e26. doi:10.2459/JCM.0000000000000377

4. Ranpura V, Hapani S, Chuang J, Wu S. Risk of cardiac ischemia and arterial thromboembolic events with the angiogenesis inhibitor bevacizumab in cancer patients: A meta-analysis of randomized controlled trials. Acta Oncologica. 2010;49(3):287-297. doi:10.3109/02841860903524396

5. Schmidinger M, Zielinski CC, Vogl UM, et al. Cardiac Toxicity of Sunitinib and Sorafenib in Patients With Metastatic Renal Cell Carcinoma. Journal of Clinical Oncology. 2008;26(32):5204-5212. doi:10.1200/JCO.2007.15.6331

6. Chambers TP, Santiesteban L, Gomez D, Chambers JW. Sab mediates mitochondrial dysfunction involved in imatinib mesylate-induced cardiotoxicity. Toxicology. 2017;382:24-35. doi:10.1016/j.tox.2017.03.006

7. $\mathrm{Xu} Z$ Z, Jin $\mathrm{Y}, \mathrm{Yan} \mathrm{H}$, et al. High-mobility group box 1 protein-mediated necroptosis contributes to dasatinib-induced cardiotoxicity. Toxicology Letters. 2018;296:39-47. doi:10.1016/j.toxlet.2018.08.003

8. de Angelis A, Urbanek K, Cappetta D, et al. Doxorubicin cardiotoxicity and target cells: a broader perspective. Cardio-Oncology. 2016;2(1):2. doi:10.1186/s40959-016-0012-4

9. Polk A, Vaage-Nilsen M, Vistisen K, Nielsen DL. Cardiotoxicity in cancer patients treated with 5fluorouracil or capecitabine: A systematic review of incidence, manifestations and predisposing factors. Cancer Treatment Reviews. 2013;39(8):974-984. doi:10.1016/j.ctrv.2013.03.005

10. Parker WB, Cheng YC. Metabolism and mechanism of action of 5-fluorouracil. Pharmacology \& Therapeutics. 1990;48(3):381-395. doi:10.1016/0163-7258(90)90056-8 
11. HEIDELBERGER C, CHAUDHURI NK, DANNEBERG P, et al. Fluorinated Pyrimidines, A New Class of Tumour-Inhibitory Compounds. Nature. 1957;179(4561):663-666. doi:10.1038/179663a0

12. Polk A, Vistisen K, Vaage-Nilsen M, Nielsen DL. A systematic review of the pathophysiology of 5fluorouracil-induced cardiotoxicity. BMC Pharmacology and Toxicology. 2014;15(1):47. doi:10.1186/2050-6511-15-47

13. Kosmas C, Kallistratos MS, Kopterides P, et al. Cardiotoxicity of fluoropyrimidines in different schedules of administration: a prospective study. Journal of cancer research and clinical oncology. 2008;134(1):75-82. doi:10.1007/S00432-007-0250-9

14. Matsubara I, Kamiya J, Imai S. Cardiotoxic effects of 5-fluorouracil in the guinea pig. Japanese journal of pharmacology. 1980;30(6):871-879. doi:10.1254/jjp.30.871

15. Stevenson DL, Mikhailidis DP, Gillett DS. Cardiotoxicity of 5-fluorouracil. Lancet (London, England). 1977;2(8034):406-407. doi:10.1016/s0140-6736(77)90339-7

16. Cwikiel M, Eskilsson J, Albertsson M, Stavenow L. The influence of 5-fluorouracil and methotrexate on vascular endothelium. An experimental study using endothelial cells in the culture. Annals of Oncology. 1996;7(7):731-737. doi:10.1093/oxfordjournals.annonc.a010723

17. Gu J, Hu W, Song Z ping, Chen Y guang, Zhang D dong, Wang C qian. Resveratrol-induced autophagy promotes survival and attenuates doxorubicin-induced cardiotoxicity. International Immunopharmacology. 2016;32:1-7. doi:10.1016/j.intimp.2016.01.002

18. Matouk Al, Taye A, Heeba GH, El-Moselhy MA. Quercetin augments the protective effect of losartan against chronic doxorubicin cardiotoxicity in rats. Environmental Toxicology and Pharmacology. 2013;36(2):443-450. doi:10.1016/j.etap.2013.05.006

19. Kozluca O, Olcay E, Sürücü S, Güran Z, Kulaksiz T, Üskent N. Prevention of doxorubicin induced cardiotoxicity by catechin. Cancer Letters. 1996;99(1):1-6. doi:10.1016/0304-3835(95)04021-8

20. Katamura M. Curcumin Attenuates Doxorubicin-Induced Cardiotoxicity by Inducing Autophagy via the Regulation of JNK Phosphorylation. Journal of Clinical \& Experimental Cardiology. 2014;05(09). doi:10.4172/2155-9880.1000337

21. Aryal P, Kim K, Park PH, Ham S, Cho J, Song K. Baicalein induces autophagic cell death through AMPK/ULK1 activation and downregulation of mTORC1 complex components in human cancer cells. FEBS Journal. 2014;281(20):4644-4658. doi:10.1111/febs.12969

22. Prietsch RF, Monte LG, da Silva FA, et al. Genistein induces apoptosis and autophagy in human breast MCF-7 cells by modulating the expression of proapoptotic factors and oxidative stress enzymes. Molecular and Cellular Biochemistry. 2014;390(1-2):235-242. doi:10.1007/s11010-0141974-X

23. Yu W, Sun H, Zha W, et al. Apigenin Attenuates Adriamycin-Induced Cardiomyocyte Apoptosis via the PI3K/AKT/mTOR Pathway. Evidence-Based Complementary and Alternative Medicine. 2017;2017:19. doi:10.1155/2017/2590676

24. Chopra S, Pillai KK, Husain SZ, Girl DK. Propolis protects against doxorubicin-induced myocardiopathy in rats. Experimental and molecular pathology. 1995;62(3):190-198. 
doi:10.1006/EXMP.1995.1021

25. de Groot AC. Propolis: A review of properties, applications, chemical composition, contact allergy, and other adverse effects. Dermatitis. 2013;24(6):263-282. doi:10.1097/DER.0000000000000011

26. Watanabe MAE, Amarante MK, Conti BJ, Sforcin JM. Cytotoxic constituents of propolis inducing anticancer effects: a review. Journal of Pharmacy and Pharmacology. 2011;63(11):1378-1386. doi:10.1111/j.2042-7158.2011.01331.x

27. Búfalo MC, Candeias JMG, Sforcin JM. In Vitro Cytotoxic Effect of Brazilian Green Propolis on Human Laryngeal Epidermoid Carcinoma (HEp-2) Cells. Evidence-Based Complementary and Alternative Medicine. 2009;6(4):483-487. doi:10.1093/ecam/nem147

28. Chan GCF, Cheung KW, Sze DMY. The Immunomodulatory and Anticancer Properties of Propolis. Clinical Reviews in Allergy \& Immunology. 2013;44(3):262-273. doi:10.1007/s12016-012-8322-2

29. Orsi RDO, Sforcin JM, Funari SRC, Fernandes Junior A, Bankova V. Synergistic effect of propolis and antibiotics on the Salmonella Typhi. Brazilian Journal of Microbiology. 2006;37(2):108-112. doi:10.1590/S1517-83822006000200002

30. Búfalo MC, Figueiredo AS, de Sousa JPB, Candeias JMG, Bastos JK, Sforcin JM. Anti-poliovirus activity of Baccharis dracunculifolia and propolis by cell viability determination and real-time PCR. Journal of Applied Microbiology. 2009;107(5):1669-1680. doi:10.1111/j.1365-2672.2009.04354.x

31. SFORCIN JM, FERNANDES JÚNIOR A, LOPES CAM, FUNARI SRC, BANKOVA V. Seasonal effect of brazilian propolis on Candida albicans and Candida tropicalis. Journal of Venomous Animals and Toxins. 2001;7(1):139-144. doi:10.1590/S0104-79302001000100009

32. Freitas SF, Shinohara L, Sforcin JM, Guimarães S. In vitro effects of propolis on Giardia duodenalis trophozoites. Phytomedicine. 2006;13(3):170-175. doi:10.1016/j.phymed.2004.07.008

33. Braik A, Lahouel M, Merabet R, Djebar MR, Morin D. Myocardial protection by propolis during prolonged hypothermic preservation. Cryobiology. 2019;88:29-37.

doi:10.1016/j.cryobiol.2019.04.003

34. Ekhteiari Salmas R, Durdagi S, Gulhan MF, Duruyurek M, Abdullah HI, Selamoglu Z. The effects of pollen, propolis, and caffeic acid phenethyl ester on tyrosine hydroxylase activity and total RNA levels in hypertensive rats caused by nitric oxide synthase inhibition: experimental, docking and molecular dynamic studies. Journal of Biomolecular Structure and Dynamics. 2018;36(3):609-620. doi:10.1080/07391102.2017.1288660

35. Afrouzan $\mathrm{H}$, Tahghighi A, Zakeri S, Es-Haghi A. Chemical composition and antimicrobial activities of Iranian propolis. Iranian Biomedical Journal. 2018;22(1):50-65. doi:10.22034/ibj.22.1.50

36. Asgharpour F, Moghadamnia AA, Kazemi S, Nouri HR, Motallebnejad M. Applying GC-MS analysis to identify chemical composition of Iranian propolis prepared with different solvent and evaluation of its biological activity. Caspian Journal of Internal Medicine. 2020;11(2):191-198. doi:10.22088/cjim.11.2.191

37. Pirzadeh M, Barary M, Hosseini SM, Kazemi S, Moghadamnia AA. Ameliorative effect of Alpinia officinarum Hance extract on nonylphenol-induced reproductive toxicity in male rats. Andrologia. 
2021;53(6). doi:10.1111/AND.14063

38. Patel V, Upaganlawar A, Zalawadia R, Balaraman R. Cardioprotective effect of melatonin against isoproterenol induced myocardial infarction in rats: A biochemical, electrocardiographic and histoarchitectural evaluation. European Journal of Pharmacology. 2010;644(1-3):160-168. doi:10.1016/J.EJPHAR.2010.06.065

39. Miller NJ, Rice-Evans C, Davies MJ, Gopinathan V, Milner A. A Novel Method for Measuring Antioxidant Capacity and its Application to Monitoring the Anti-oxidant Status in Premature Neonates. Clinical Science. 1993;84(4):407-412. doi:10.1042/cs0840407

40. Nouri HR, Sankian M, Afsharzadeh D, Varasteh A. Immunotherapy with a recombinant hybrid molecule alleviates allergic responses more efficiently than an allergenic cocktail or pollen extract in a model of Chenopodium album allergy. International Archives of Allergy and Immunology. 2013;161(4):325-332. doi:10.1159/000347136

41. Pfaffl MW. A new mathematical model for relative quantification in real-time RT-PCR. Nucleic Acids Research. 2001;29(9):45e-445. doi:10.1093/nar/29.9.e45

42. Sameni HR, Yosefi S, Alipour M, et al. Co-administration of 5FU and propolis on AOM/DSS induced colorectal cancer in BALB-c mice. Life sciences. 2021;276. doi:10.1016/J.LFS.2021.119390

43. Manu KA, Shanmugam MK, Ramachandran L, et al. Isorhamnetin augments the anti-tumor effect of capecitabine through the negative regulation of NF-KB signaling cascade in gastric cancer. Cancer letters. 2015;363(1):28-36. doi:10.1016/J.CANLET.2015.03.033

44. Yang C, Song J, Hwang S, Choi J, Song G, Lim W. Apigenin enhances apoptosis induction by 5fluorouracil through regulation of thymidylate synthase in colorectal cancer cells. Redox biology. 2021;47. doi:10.1016/J.REDOX.2021.102144

45. Rašković A, Stilinović N, Kolarović J, Vasović V, Vukmirović S, Mikov M. The protective effects of silymarin against doxorubicin-induced cardiotoxicity and hepatotoxicity in rats. Molecules (Basel, Switzerland). 2011;16(10):8601-8613. doi:10.3390/MOLECULES16108601

46. El-Sayyad HI, Ismail MF, Shalaby FM, et al. Histopathological effects of cisplatin, doxorubicin and 5flurouracil (5-FU) on the liver of male albino rats. International journal of biological sciences. 2009;5(5):466-473. doi:10.7150/IJBS.5.466

47. von Bültzingslöwen I, Adlerberth I, Wold AE, Dahlén G, Jontell M. Oral and intestinal microflora in 5fluorouracil treated rats, translocation to cervical and mesenteric lymph nodes and effects of probiotic bacteria. Oral microbiology and immunology. 2003;18(5):278-284. doi:10.1034/J.1399302X.2003.00075.X

48. Aygun H, Gul SS. Cardioprotective effect of melatonin and agomelatine on doxorubicin-induced cardiotoxicity in a rat model: an electrocardiographic, scintigraphic and biochemical study. Bratislavske lekarske listy. 2019;120(4):249-255. doi:10.4149/BLL_2019_045

49. Attia YA, El-Hanoun AM, Bovera F, Monastra G, El-Tahawy WS, Habiba HI. Growth performance, carcass quality, biochemical and haematological traits and immune response of growing rabbits as 
affected by different growth promoters. Journal of animal physiology and animal nutrition. 2014;98(1):128-139. doi:10.1111/JPN.12056

50. Yonar ME, Yonar SM, Pala A, Silici S, Sa冈lam N. Trichlorfon-induced haematological and biochemical changes in Cyprinus carpio: ameliorative effect of propolis. Diseases of aquatic organisms. 2015;114(3):209-216. doi:10.3354/DA002866

51. Anghel N, Cotoraci C, Ivan A, et al. Chrysin attenuates cardiomyocyte apoptosis and loss of intermediate filaments in a mouse model of mitoxantrone cardiotoxicity. Histology and histopathology. 2015;30(12):1465-1475. doi:10.14670/HH-11-641

52. Gu J, Huang H, Liu C, et al. Pinocembrin inhibited cardiomyocyte pyroptosis against doxorubicininduced cardiac dysfunction via regulating Nrf2/Sirt3 signaling pathway. International immunopharmacology. 2021;95. doi:10.1016/J.INTIMP.2021.107533

53. Lofthus DM, Stevens SR, Armstrong PW, Granger CB, Mahaffey KW. Pattern of liver enzyme elevations in acute ST-elevation myocardial infarction. Coronary artery disease. 2012;23(1):22-30. doi:10.1097/MCA.0B013E32834E4EF1

54. Djakpo DK, Wang ZQ, Shrestha M. The significance of transaminase ratio (AST/ALT) in acute myocardial infarction. Archives of Medical Sciences Atherosclerotic Diseases. 2020;5:e279. doi:10.5114/AMSAD.2020.103028

55. Lotfi M, Kazemi S, Shirafkan F, et al. The protective effects of quercetin nano-emulsion on intestinal mucositis induced by 5 -fluorouracil in mice. Biochemical and biophysical research communications. 2021;585:75-81. doi:10.1016/J.BBRC.2021.11.005

56. Alyane M, Kebsa LBW, Boussenane HN, Rouibah H, Lahouel M. Cardioprotective effects and mechanism of action of polyphenols extracted from propolis against doxorubicin toxicity. Pakistan Journal of Pharmaceutical Sciences. 2008;21(3).

57. Laaroussi $H$, Bakour M, Ousaaid D, et al. Protective Effect of Honey and Propolis against GentamicinInduced Oxidative Stress and Hepatorenal Damages. Oxidative medicine and cellular longevity. 2021;2021. doi:10.1155/2021/9719906

58. Kumar S, Gupta RK, Samal N. 5-fluorouracil induced cardiotoxicity in albino rats. Materia medica Polona Polish journal of medicine and pharmacy. 1995;27(2):63-66.

59. Gelen V, Şengül E, Yıldııım S, Senturk E, Tekin S, Kükürt A. The protective effects of hesperidin and curcumin on 5-fluorouracil-induced nephrotoxicity in mice. Environmental science and pollution research international. 2021;28(34):47046-47055. doi:10.1007/S11356-021-13969-5

60. Jalali M, Ranjbar T, Mosallanezhad Z, et al. Effect of Propolis Intake on Serum C-Reactive Protein (CRP) and Tumor Necrosis Factor-alpha (TNF-a) Levels in Adults: A Systematic Review and MetaAnalysis of Clinical Trials. Complementary therapies in medicine. 2020;50.

doi:10.1016/J.CTIM.2020.102380

\section{Figures}




\section{Figure 1}

The GC-MS analysis of the propolis ethanolic extract. Sample peaks were detected as pinostrobin chalcone (32.066 s, $15.099 \%$ of total), galangin (33.256 s, 55.509\% of total), tectochrysin (34.973 s, $13.216 \%$ of total), and naringenin (36.552 s, $16.177 \%$ of total).

Figure 2

Effect of different doses of propolis on the viability of rat myocardium (H9C2(2-1)) cell line. All values are expressed in mean \pm SD. ${ }^{\star \star \star \star}$ indicate $p<0.0001$.

Figure 3

Effect of 5-flurouracil and propolis administration on the relative heart weight of rats. Values are expressed as mean \pm standard deviation (SD). Groups: Control, Normal saline; 5-FU, 5-FU $125 \mathrm{mg} / \mathrm{kg}$; 5FU + Pro, 5-FU 125 mg/kg + Propolis ethanolic extract 250 mg/kg/d; 5-FU + CLC, 5-FU 125 mg/kg + Colchicine $5 \mathrm{mg} / \mathrm{kg} / \mathrm{d}$. ${ }^{* \star *}$ indicate $\mathrm{p}<0.001$.

\section{Figure 4}

ECG images of study rats. Groups: Control, Normal saline; 5-FU, 5-FU 125 mg/kg; 5-FU + Pro, 5-FU 125 $\mathrm{mg} / \mathrm{kg}+$ Propolis ethanolic extract $250 \mathrm{mg} / \mathrm{kg} / \mathrm{d} ; 5-\mathrm{FU}+\mathrm{CLC}, 5-\mathrm{FU} 125 \mathrm{mg} / \mathrm{kg}+$ Colchicine $5 \mathrm{mg} / \mathrm{kg} / \mathrm{d}$.

Figure 5

Effect of 5-flurouracil and propolis administration on the AST/ALT ratio of rats. Values are expressed as mean \pm standard deviation (SD). Groups: Control, Normal saline; 5-FU, 5-FU 125 mg/kg; 5-FU + Pro, 5-FU 
$125 \mathrm{mg} / \mathrm{kg}$ + Propolis ethanolic extract $250 \mathrm{mg} / \mathrm{kg} / \mathrm{d} ; 5-\mathrm{FU}+\mathrm{CLC}, 5-\mathrm{FU} 125 \mathrm{mg} / \mathrm{kg}$ + Colchicine 5 $\mathrm{mg} / \mathrm{kg} / \mathrm{d}^{* *}{ }^{* \star *}$, and ${ }^{* \star \star *}$ indicate $\mathrm{p}<0.01, \mathrm{p}<0.001$, and $\mathrm{p}<0.0001$, respectively.

Figure 6

Effect of 5-flurouracil and propolis administration on the A) TAC, B) MDA, and C) CAT status of the serum samples. Values are expressed as mean \pm standard deviation (SD). Groups: Control, Normal saline; 5-FU, 5 -FU 125 mg/kg; 5-FU + Pro, 5-FU 125 mg/kg + Propolis ethanolic extract 250 mg/kg/d; 5-FU + CLC, 5-FU $125 \mathrm{mg} / \mathrm{kg}+$ Colchicine $5 \mathrm{mg} / \mathrm{kg} / \mathrm{d} .{ }^{*}{ }^{* \star}{ }^{* * *}$, and ${ }^{* \star *}$ indicate $\mathrm{p}<0.05, \mathrm{p}<0.01, \mathrm{p}<0.001$, and $\mathrm{p}<0.0001$, respectively.

Figure 7

Effect of 5-fluorouracil and propolis administration on the histopathological changes of heart tissue samples. Groups: Control, Normal saline; 5-FU, 5-FU 125 mg/kg; 5-FU + Pro, 5-FU 125 mg/kg + Propolis ethanolic extract $250 \mathrm{mg} / \mathrm{kg} / \mathrm{d} ; 5$-FU + CLC, 5 -FU $125 \mathrm{mg} / \mathrm{kg}+$ Colchicine $5 \mathrm{mg} / \mathrm{kg} / \mathrm{d}$. Normal conditions in the Control group. Note hyperemia (rightward arrows), necrosis (downward arrows), and hyalinization (leftward arrows) in the 5-FU, 5-FU + Pro, and 5-FU + CLC groups. Hematoxylin and Eosin (H\&E) staining $x$ 100 magnification.

Figure 8

Effect of 5-fluorouracil and propolis administration on the expression of A) TNF-a and B) COX-2. Values are expressed as mean \pm standard deviation (SD). Groups: Control, Normal saline; 5-FU, 5-FU $125 \mathrm{mg} / \mathrm{kg}$; 5-FU + Pro, 5-FU 125 mg/kg + Propolis ethanolic extract 250 mg/kg/d; 5-FU + CLC, 5-FU 125 mg/kg + Colchicine $5 \mathrm{mg} / \mathrm{kg} / \mathrm{d}$. ${ }^{*}$ indicate $\mathrm{p}<0.01$. 